\title{
Analytical Determination of DC-Bus Utilization Limits in Multiphase VSI Supplied AC Drives
}

\author{
Emil Levi, Senior Member, IEEE, Drazen Dujic, Student Member, IEEE, Martin Jones, Member, IEEE, \\ and Gabriele Grandi, Member, IEEE
}

\begin{abstract}
Two-level multiphase voltage source inverters (VSIs) are typically used as the supply for multiphase machines. Such machines are often with concentrated winding in which case, certain low-order stator current harmonics are injected to provide torque enhancement. Also, a multimotor drive system can be realized by connecting a number of multiphase machines in series, using phase transposition while supplying the whole system from a single multiphase VSI. In both situations, it is important to know the limits of the inverter operation in the linear modulation region. This paper develops a simple method that enables analytical determination of the boundaries of the linear modulation region for all multiphase inverters with a prime number of phases. The limits are independent of the actual pulse width modulation (PWM) method utilized, and are equally applicable to both carrier-based and space vector PWM techniques. Theoretical considerations are verified experimentally using the five-phase and seven-phase VSI rigs.
\end{abstract}

Index Terms-Dc-bus utilization, multiphase ac drives, multiphase voltage source inverters (VSIs), pulse width modulation (PWM).

\section{INTRODUCTION}

M ULTIPHASE drives are nowadays considered as serious contenders for various variable-speed applications because of the benefits that they offer when compared to their three-phase counterparts [1]. Typical examples include naval propulsion systems, "more-electric" aircraft and electric and hybrid vehicles [1]. Variable-speed multiphase drives are most commonly supplied from a two-level multiphase voltage source inverter (VSI), where the number of inverter legs usually equals the number of machine phases (the alternative configuration, which is based on a separate $\mathrm{H}$-bridge inverter for each phase, is typical for safety-critical applications, [2]).

An adequate method of pulse width modulation (PWM) is required to operate the VSI properly, and therefore, fully exploit potential advantages offered by multiphase machines. The required output voltage of a PWM-controlled VSI depends on the type of the stator winding that a multiphase machine is equipped

Manuscript received July 16, 2007; revised September 17, 2007. This work was supported in part by the Engineering and Physical Sciences Research Council (EPSRC) under Grant EP/C007395, in part by Semikron, Ltd., U.K., in part by MOOG, Italy, and in part by Verteco, Finland. Paper no. TEC-00239-2007.

E. Levi, D. Dujic, and M. Jones are with the School of Engineering, Liverpool John Moores University, Liverpool L3 3AF, U.K. (e-mail: e.levi@ljmu.ac.uk; d.dujic@2006.ljmu.ac.uk; m.jones2@1jmu.ac.uk).

G. Grandi is with the Department of Electrical Engineering, University of Bologna, 40136 Bologna, Italy (e-mail: gabriele.grandi@mail.ing.unibo.it).

Color versions of one or more of the figures in this paper are available online at http://ieeexplore.ieee.org.

Digital Object Identifier 10.1109/TEC.2008.921557 with. If the winding is sinusoidally distributed, the VSI must supply the machine with fundamental voltage harmonic only, without any low-order harmonics. Numerous PWM methods, aimed at sinusoidal output voltage generation with multiphase inverters, have been developed in recent times [3]-[10]. Most of these works have discussed five-phase and seven-phase VSIs.

If a machine with sinusoidal winding distribution is supplied from a multiphase VSI, determination of the dc-bus utilization in the linear modulation region is straightforward. It has been shown that, for a five-phase VSI, both carrier-based methods with the zero-sequence injection and the space vector PWM method allow an increase of $5.15 \%$ in the dc-bus utilization, when compared to the simplest sinusoidal modulation without any zero-sequence signal injection [6], [10]. In case of a sevenphase VSI, an increase of $2.57 \%$ in the dc-bus utilization is achievable, again with both carrier-based and space vector PWM [5], [7].

The number of phases $n$ of the machine/VSI is further assumed to be a prime number. Such a multiphase machine (VSI) can be modeled using vector space decomposition (VSD) [11]. Assuming star connected stator winding with isolated neutral, modeling leads to the representation of the machine/inverter in $(n-1) / 2$ mutually orthogonal and decoupled planes. Earlier described situation, which arises in machines with sinusoidal stator winding distribution, means that only the first plane $\left(d_{1}-q_{1}\right)$ of $(n-1) / 2$ planes is excited, while the inverter output voltage is zero in all the other planes (neglecting switching harmonics). The situation, however, changes substantially if a machine is with the concentrated stator winding. In such a case, all odd supply harmonics of the order lower than the phase number $n$ can be utilized for torque production (for example, the first and the third in a five-phase machine, the first, the third, and the fifth in a seven-phase machine, etc.). As far as the VSI is concerned, this means that it has to generate a multifrequency output voltage, with, in principle, one voltage component (harmonic) per each of the $(n-1) / 2$ planes $\left(d_{1}-q_{1}, d_{2}-q_{2}, d_{3}-q_{3}, \ldots\right)$. Appropriate PWM-control schemes for such output voltage generation with VSIs have also been developed, for example, for five-phase VSIs [12]-[14].

The third situation that may arise is the use of multiphase machines with an appropriate series connection of stator windings and the supply coming from a single multiphase VSI [15], [16]. Phase transposition, introduced in the series connection, essentially leads to independent control of, in general, $(n-1) / 2$ multiphase machines. This requires that the inverter generates at the output again one voltage component per each of the $(n-1) / 2$ 
planes. The only but important difference as compared to the case of a single multiphase machine with concentrated winding is that in this case, required voltage components in different planes are completely unrelated. Appropriate PWM schemes for series-connected multiphase machines, that enable multifrequency output voltage generation, have been developed in [17] and [18].

On the basis of the explanations given before, it is obvious that from the inverter point of view, supply of a machine with concentrated stator winding is the same as the supply of a seriesconnected multiphase multimotor drive system. In both cases, the VSI has to generate an output voltage that contains $(n-$ 1)/2 voltage components (harmonics), which belong to different planes [one per each of the $(n-1) / 2$ planes].

In any inverter-fed drive, it is of utmost importance to determine the limit(s) of the dc-bus voltage utilization in the linear modulation region. For example, if the inverter dc-bus voltage is of a certain value, it is crucial to understand how much of the available dc-bus voltage can be allocated to the third harmonic injection for a given fundamental in a concentrated winding machine, or how much can be allocated to the second machine in a series-connected five-phase two-motor drive for a given fundamental of the first machine. However, regardless of the extensive work that has been done regarding PWM techniques for multifrequency output voltage generation [12]-[14], [17], [18], there is no indication that dc-bus utilization has been explored in a systematic manner.

The aim of this paper is, therefore, to present a simple analytical method, which enables determination of boundaries of the linear modulation region for any multiphase VSI with an odd (prime) number of phases. Since series-connected multiphase machines can have completely arbitrary voltage requirements, only magnitudes of phase voltages of machines are considered (frequencies and phase shifts are disregarded), and appropriate relations with the dc-bus voltage are established. Detailed considerations are given for the five-phase and the seven-phase case, with subsequent generalization to higher phase numbers. An important characteristic of the presented method is its complete independence from the applied PWM technique. Theoretical study is fully verified experimentally using custom designed five-phase and seven-phase experimental rigs.

\section{Multifrequency Output Voltage Generation With MULTIPHASE VSIS}

As noted, VSD modeling approach enables representation of the machine/inverter in $(n-1) / 2$ mutually orthogonal and decoupled planes. Low-order harmonics of the inverter supply map into different planes, according to the well-known rules [11]. Table I illustrates harmonic mapping for a five-phase and a seven-phase system. The lowest harmonics that produce a torque ripple are the 9 th and 11th in a five-phase machine and 13 th and 15 th in a seven-phase machine. They map into the first $\left(d_{1}-q_{1}\right)$ plane together with the fundamental. However, other low-order harmonics map into other planes: the third and the seventh of a five-phase VSI and the fifth and the ninth of a
TABLE I

HARMONIC MAPPING INTO DifFERENT Planes FOR FIVE-PHASE AND SEVEN-PHASE SySTEMS $(k=0,1,2,3, \ldots)$

\begin{tabular}{|c|c|c|}
\hline & Five-phase system & Seven-phase system \\
\hline Plane & & \\
\hline$d_{1}-q_{1}$ & $10 k \pm 1(\mathbf{1}, 9,11 \ldots)$ & $14 k \pm 1(\mathbf{1}, 13,15 \ldots)$ \\
\hline$d_{2}-q_{2}$ & $10 k \pm 3(\mathbf{3}, 7,13 \ldots)$ & $14 k \pm 5(\mathbf{5}, 9,19 \ldots)$ \\
\hline$d_{3}-q_{3}$ & $\mathrm{n} / \mathrm{a}$ & $14 k \pm 3(\mathbf{3}, 11,17 \ldots)$ \\
\hline Zero-sequence & $5(2 k+1)(5,15 \ldots)$ & $7(2 k+1)(7,21 \ldots)$ \\
\hline
\end{tabular}

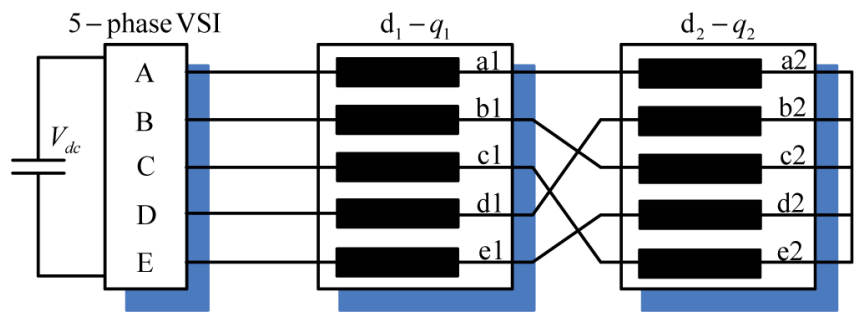

Fig. 1. Illustration of the required VSI output voltage generation in two planes of the five-phase system (two-motor series-connected drive system or a concentrated winding machine with the third harmonic injection).

seven-phase VSI map into the second $\left(d_{2}-q_{2}\right)$ plane, while the 3rd and the 11th harmonic of a seven-phase VSI map into the third $\left(d_{3}-q_{3}\right)$ plane. The lowest order harmonic in each plane can be used to enhance the torque production (the third in the five-phase and the third and the fifth in the seven-phase drive). Harmonic mapping, depicted in Table I, is the consequence of the decoupling transformation matrix for multiphase systems [19].

As far as series-connected multiphase drives are concerned, mapping of fundamentals of $(n-1) / 2$ machines into corresponding $(n-1) / 2$ planes is the consequence of the physical phase transposition introduced in the series connection of stator windings [15], [16]. Hence, from the inverter point of view, ${ }^{1} \mathrm{a}$ series-connected multimotor drive system and a concentrated winding machine with stator current injection can be both represented with the same schematic diagrams. This is illustrated in Figs. 1 and 2 for a five-phase and a seven-phase system, which constitute the basis for further development. The analogy is explained in more detail in Appendix A for the five-phase case of Fig. 1.

\section{DC-Bus UtiLIZATION IN MultiPhase VSIs}

\section{A. Three-Phase System}

A three-phase system is briefly reviewed first since subsequent analysis relies on the same principles. Maximum level of the dc-bus voltage utilization is customarily determined for a three-phase VSI by an analysis of the line voltage of the machine. To start with, modulation index $M_{i}$ is defined as the ratio

\footnotetext{
${ }^{1}$ It is important to realize that the two cases are only equivalent from the inverter output voltage generation point of view. While for series-connected multimotor drives, Fig. 1 and 2 include representation of physical stator windings, it is not so for concentrated winding machines in which case, these are some fictitious windings that do not exist as separate entities in reality.
} 


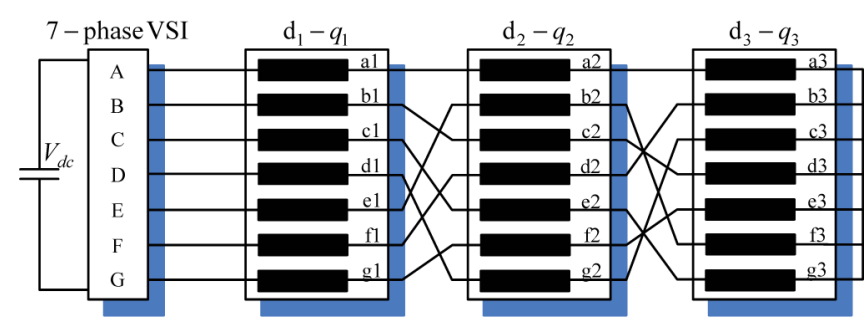

Fig. 2. Illustration of the required VSI output voltage generation in three planes of the seven-phase system (three-motor series-connected drive system or a concentrated winding machine with the fifth and the third harmonic injection).

of the phase voltage fundamental peak value $V_{1}$ and one-half of the dc-bus voltage $V_{\mathrm{dc}}$

$$
M_{i}=\frac{V_{1}}{0.5 V_{\mathrm{dc}}} .
$$

Using this definition, phase and line voltages of a machine can be expressed as functions of the modulation index. For a three-phase system, maximum utilization of the dc-bus voltage (i.e., limit of the linear modulation region) is reached when peak value of the line voltage becomes equal to the dc-bus voltage. Since in a three-phase system, all line voltages are of the same magnitude [phasor diagram is shown in Fig. 3(a)], it is sufficient to consider only one line voltage, referenced to phase " $a$." From Fig. 3(a) and (1), simple trigonometry yields

$$
\left|\underline{V}_{a b}\right|=2 M_{i} 0.5 V_{\mathrm{dc}} \cos \left(\frac{\pi}{6}\right)=V_{\mathrm{dc}} .
$$

From (2), the maximum value of the modulation index is

$$
M_{\max }=\frac{1}{\cos (\pi / 6)}=1.1547 .
$$

This is the well-known maximum value of the modulation index for continuous PWM methods [20]. This basic principle is now extended to multiphase systems.

\section{B. Multiphase Systems}

In a five-phase system, there are two different groups of line voltages, with regard to their magnitudes [see Fig. 3(b)]. The first group is the adjacent line voltages. Their magnitude, as a function of the modulation index, is given with

$$
\left|\underline{V}_{a b}\right|=2 M_{i} 0.5 V_{\mathrm{dc}} \cos \left(\frac{3 \pi}{10}\right) .
$$

Similarly, magnitude of nonadjacent line voltages can be expressed as [see Fig. 3(b)]

$$
\left|\underline{V}_{a c}\right|=2 M_{i} 0.5 V_{\mathrm{dc}} \cos \left(\frac{\pi}{10}\right) \text {. }
$$

As with a three-phase system, limit of the linear modulation region is obtained when peak value of the largest line voltage reaches value of the dc-bus voltage. Thus, by equating (5) to the value of the dc-bus voltage, one finds that the maximum value of the modulation index in a five-phase system is

$$
M_{\max }=\frac{1}{\cos (\pi / 10)}=1.0515
$$

the value already established in [6] and [10]. Finally, in a sevenphase system [see Fig. 3(c)], there are three different groups of line voltages, and their magnitudes (in ascending order) can be expressed from Fig. 3(c) as

$$
\begin{aligned}
& \left|\underline{V}_{a b}\right|=2 M_{i} 0.5 V_{\mathrm{dc}} \cos \left(\frac{5 \pi}{14}\right) \\
& \left|\underline{V}_{a c}\right|=2 M_{i} 0.5 V_{\mathrm{dc}} \cos \left(\frac{3 \pi}{14}\right) \\
& \left|\underline{V}_{a d}\right|=2 M_{i} 0.5 V_{\mathrm{dc}} \cos \left(\frac{\pi}{14}\right) .
\end{aligned}
$$

In the same manner as before, the maximum value of the modulation index in the linear modulation region is obtained as equal to $M_{\max }=1 / \cos (\pi / 14)=1.0257$ [5], [7].

The values of the maximum modulation index in the limit of the linear modulation region, established here and already known in literature [5]-[7], [10], are valid as long as the inverters are required to operate with sinusoidal output voltage (i.e., reference voltages are zero in all the planes other than $d_{1}-q_{1}$ ). As shown in [10], the maximum modulation index is related to the phase number $n$ through $M_{\max }=1 / \cos (\pi / 2 n)$.

\section{Multifrequency Output Voltage Generation in a Five-Phase System}

In this case, the inverter has to generate a voltage component in both planes of Fig. 1. Dc-bus voltage utilization is, therefore, not function of a single modulation index any more. Let the modulation indexes in the two planes of Fig. 1 be denoted as $M_{1}$ and $M_{2}$, respectively. Here, $M_{2}$ is either firmly tied to the $M_{1}$ (concentrated winding machine) or is completely independent of $M_{1}$ (series-connected two-motor drive).

By analyzing Fig. 1, one establishes that all inverter line voltages are a sum of an adjacent (respectively, nonadjacent) line voltage in the $d_{1}-q_{1}$ plane and a nonadjacent (respectively, adjacent) line voltage in the $d_{2}-q_{2}$ plane. For example, inverter $v_{A B}$ and $v_{A C}$ voltages can be expressed as

$$
v_{A B}=v_{A}-v_{B}=\left(v_{a 1}+v_{a 2}\right)-\left(v_{b 1}+v_{c 2}\right)=v_{a b 1}+v_{a c 2}
$$

$v_{A C}=v_{A}-v_{C}=\left(v_{a 1}+v_{a 2}\right)-\left(v_{c 1}+v_{e 2}\right)=v_{a c 1}+v_{a e 2}$.

The worst-case scenario is considered further on. Since two individual line voltages in planes $d_{1}-q_{1}$ and $d_{2}-q_{2}$ [righthand side in (8) and (9)] are, in general, unrelated and of arbitrary frequencies, magnitudes, and phase shifts, the worst possible situation arises when these voltages reach the peak values in the same time instant. Hence, to establish limits of the dc-bus utilization, one substitutes expressions (4) and (5) into (8) and (9)

$$
\begin{aligned}
& \left|v_{A B}\right|=M_{1} V_{d c} \cos \left(\frac{3 \pi}{10}\right)+M_{2} V_{\mathrm{dc}} \cos \left(\frac{\pi}{10}\right) \leq V_{\mathrm{dc}} \\
& \left|v_{A C}\right|=M_{1} V_{\mathrm{dc}} \cos \left(\frac{\pi}{10}\right)+M_{2} V_{\mathrm{dc}} \cos \left(\frac{3 \pi}{10}\right) \leq V_{\mathrm{dc}} .
\end{aligned}
$$




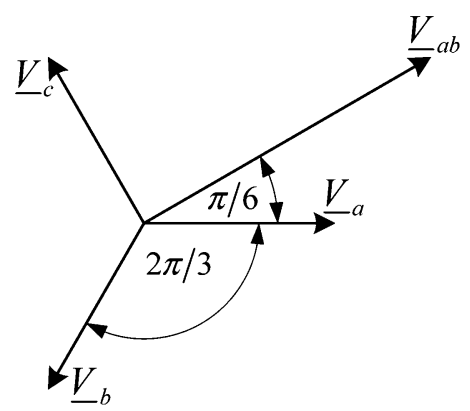

(a)

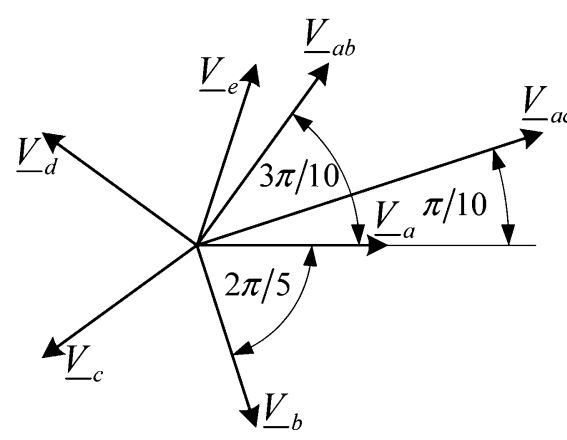

(b)

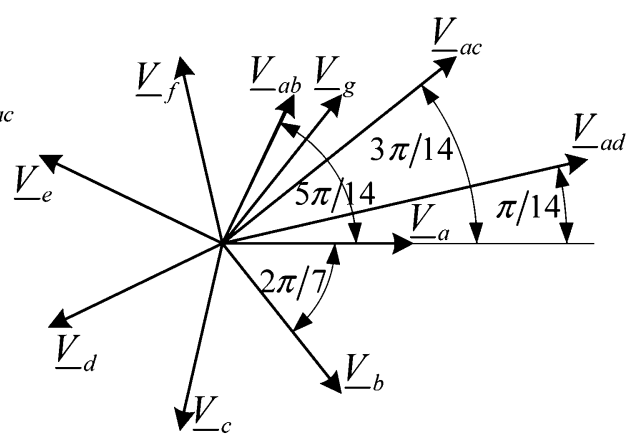

(c)

Fig. 3. Phase and line voltage phasors. (a) Three-phase system. (b) Five-phase system. (c) Seven-phase system.

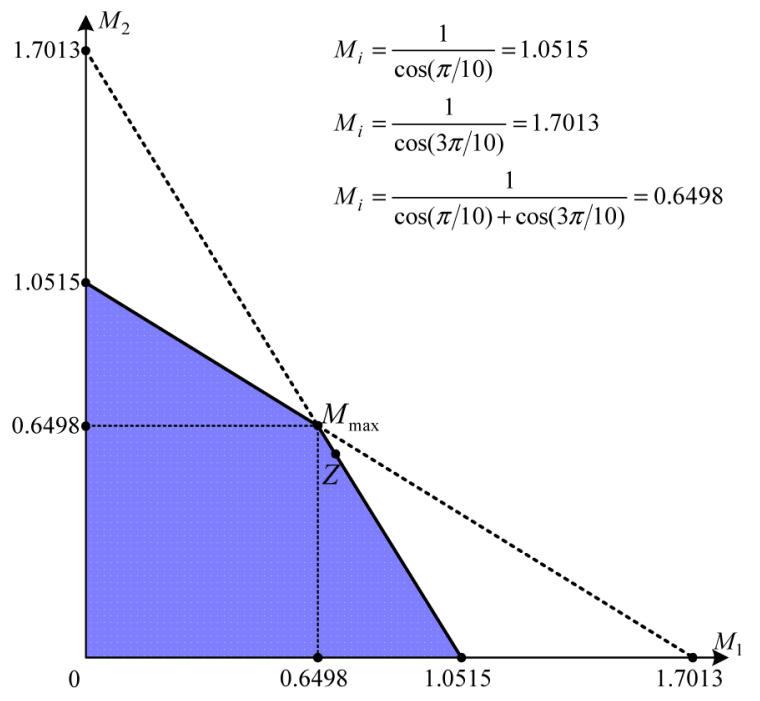

Fig. 4. Combinations of modulation indices that yield operation in the linear modulation region for a five-phase VSI (shaded area).

Rearranging (10) and (11) gives the constraints that have to be satisfied if PWM operation is to remain in the linear modulation region

$$
\begin{aligned}
& M_{1} \cos \left(\frac{3 \pi}{10}\right)+M_{2} \cos \left(\frac{\pi}{10}\right) \leq 1 \\
& M_{1} \cos \left(\frac{\pi}{10}\right)+M_{2} \cos \left(\frac{3 \pi}{10}\right) \leq 1 .
\end{aligned}
$$

These two equations define an area when plotted in a coordinate system with modulation indexes $M_{1}$ and $M_{2}$ as axes.

Graphical representation of (12) and (13) is shown in Fig. 4. Any operating point (i.e., any combination of the two modulation indices) within the shaded area is available in the linear modulation region. In the special case when modulation indexes in the two planes are equal $\left(M_{1}=M_{2}=M_{\text {max }}\right.$, one finds from (12) or (13) that $M_{\max }=0.6498$. This is a considerably larger value than the one that would have resulted had the planes in Fig. 1 not been transposed (i.e., $1.0515 / 2=0.52575$ ).

\section{Multifrequency Output Voltage Generation in a Seven-Phase System}

It is possible to establish relations between permissible values of the modulation indexes and the available dc-bus voltage for a seven-phase VSI using the same procedure as in the previous section. Due to the transposition between the three planes of Fig. 2, each inverter line voltage is a sum of three different line voltages defined in (7). Thus, the inverter line voltages are of the form

$$
\begin{aligned}
& v_{A B}=v_{A}-v_{B}=v_{a b 1}+v_{a c 2}+v_{a d 3} \\
& v_{A C}=v_{A}-v_{C}=v_{a c 1}+v_{a e 2}+v_{a g 3} \\
& v_{A D}=v_{A}-v_{D}=v_{a d 1}+v_{a g 2}+v_{a c 3} .
\end{aligned}
$$

Once more, the worst-case scenario is explored by assuming that all line voltages in each plane may reach peak values in the same time instant. The following constrains then result by combining (7) and (14)

$$
\begin{aligned}
& M_{1} \cos \left(\frac{5 \pi}{14}\right)+M_{2} \cos \left(\frac{3 \pi}{14}\right)+M_{3} \cos \left(\frac{\pi}{14}\right) \leq 1 \\
& M_{1} \cos \left(\frac{3 \pi}{14}\right)+M_{2} \cos \left(\frac{\pi}{14}\right)+M_{3} \cos \left(\frac{5 \pi}{14}\right) \leq 1 \\
& M_{1} \cos \left(\frac{\pi}{14}\right)+M_{2} \cos \left(\frac{5 \pi}{14}\right)+M_{3} \cos \left(\frac{3 \pi}{14}\right) \leq 1 .
\end{aligned}
$$

Here, $M_{1}, M_{2}$, and $M_{3}$ stand for modulation indexes of the three planes of Fig. 2. Since (15) consists of three inequalities, the possible combinations of the modulation indexes can be visualized in a 3-D space, where each modulation index is assigned to one of the axes. However, it is interesting to at first explore the availability of the dc-bus voltage under the condition that one of the three modulation indexes (in any of the three planes) is zero. Assuming, for example, that $M_{3}=0$, system (15) reduces to

$$
\begin{aligned}
& M_{1} \cos \left(\frac{5 \pi}{14}\right)+M_{2} \cos \left(\frac{3 \pi}{14}\right) \leq 1 \\
& M_{1} \cos \left(\frac{3 \pi}{14}\right)+M_{2} \cos \left(\frac{\pi}{14}\right) \leq 1
\end{aligned}
$$




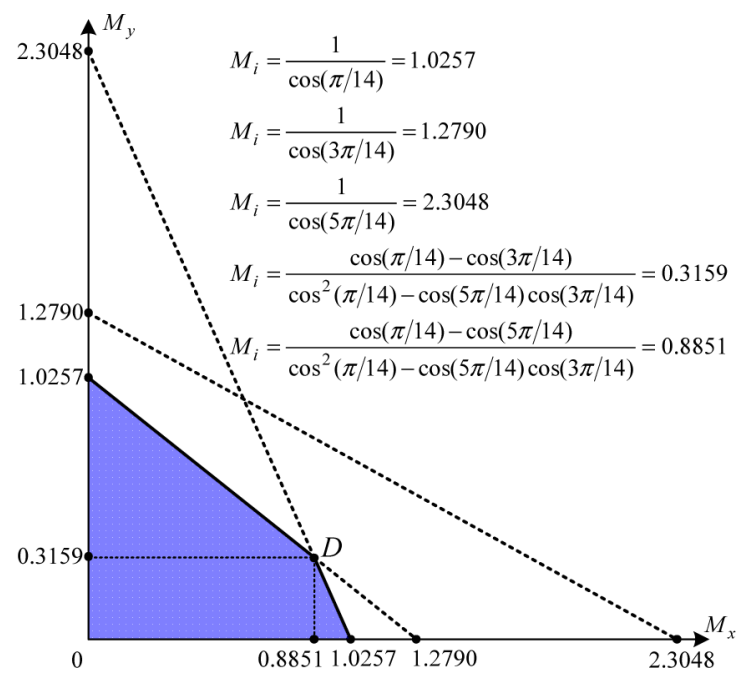

Fig. 5. Combinations of modulation indices that yield operation in the linear modulation region for a seven-phase VSI when only two planes are excited (shaded area).

$$
M_{1} \cos \left(\frac{\pi}{14}\right)+M_{2} \cos \left(\frac{5 \pi}{14}\right) \leq 1 .
$$

Solving (16) for this particular case and (15) for other two cases (when either $M_{1}=0$ or $M_{2}=0$ ), an area in 2-D plane is obtained, which determines boundaries of the available modulation indexes of a seven-phase VSI when only two (out of three) planes of Fig. 2 are excited. The solution is the same regardless of which modulation index is set to zero and is shown in Fig. 5, where the pair of axes $\left(M_{x}, M_{y}\right)$ corresponds to combinations $\left(M_{1}, M_{2}\right),\left(M_{2}, M_{3}\right)$, or $\left(M_{3}, M_{1}\right)$. It can be noted that there is an inherent asymmetry in the relations among any two of the modulation indexes of the planes. The reason is the existence of three different line voltages in each plane and the way in which these voltages are summed due to the transposition between planes. When one plane is not excited, the inverter line voltages are not all the same [in the sense of (14)] any more. It can be observed in Fig. 5 that one of the dotted lines [solution of the first row of (16)] does not play any role in the determination of the dc-bus utilization.

To illustrate the complete solution when all three planes of a seven-phase VSI are excited, three planes determined with (15) are plotted in the 3-D space using modulation indexes of the three $d-q$ planes as axes. The characteristic point obtained when all three modulation indexes are mutually equal $\left(M_{\max }=\right.$ $\left.M_{1}=M_{2}=M_{3}\right)$ is found from (15)

$$
M_{\max }=\frac{1}{\cos (\pi / 14)+\cos (5 \pi / 14)+\cos (3 \pi / 14)}=0.4565 .
$$

The value in (17) is considerably higher than the value that would have been obtained without phase transposition between the three planes of Fig. $2(1.0257 / 3=0.342)$.

Six different four-sided polygons, which bound the volume in the 3-D space, and therefore, characterize dc-bus voltage utilization, can be identified (see Fig. 6). Three of them correspond to the one shown in Fig. 5, valid when one of the modulation

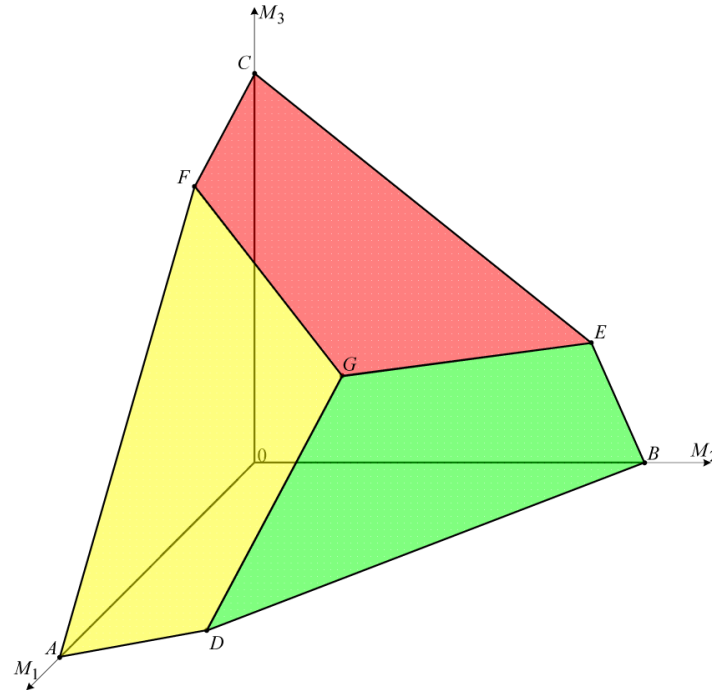

Fig. 6. Volume that defines dc-bus utilization for a seven-phase VSI with excitation in all three planes.

indexes is zero. The remaining three polygons are the result of the intersections of three different planes defined with (15), and they are shown in Fig. 6 in different shades of gray. The volume in Fig. 6 effectively relates modulation indexes of all three planes with the available value of the dc-bus voltage. As long as the operating point, defined by three modulation indexes in $M_{1}, M_{2}$, and $M_{3}$ space, is inside the enclosed volume, it is possible to generate required voltages in each plane while keeping the modulator operation in the linear region. Coordinates of characteristic points labeled with capital letters in Fig. 6 are summarized in Table II.

\section{Generalization FOR High PHASE ORder NuMBER}

On the basis of the analysis of the five-phase and the sevenphase VSI dc-bus utilization, detailed in the previous section, it is possible to generalize the approach for any $n$-phase system, described with $(n-1) / 2$ planes ( $n=$ prime number). This comes down to the determination of expressions for inverter line voltages in the same manner as for the five-phase and sevenphase systems. Normalized (with respect to the dc-bus voltage) constraints can be given in general matrix form as

$$
\left[\begin{array}{ccccc}
M_{1} & M_{2} & M_{3} & \cdots & M_{\frac{n-1}{2}} \\
M_{\frac{n-1}{2}} & M_{1} & M_{2} & \cdots & M_{\frac{n-1}{2}-1} \\
\vdots & \vdots & \vdots & \cdots & \vdots \\
M_{3} & M_{4} & M_{5} & \cdots & M_{2} \\
M_{2} & M_{3} & M_{4} & \cdots & M_{1}
\end{array}\right]\left[\begin{array}{c}
\cos \left(\frac{n-2}{2 n} \pi\right) \\
\cos \left(\frac{n-4}{2 n} \pi\right) \\
\vdots \\
\cos \left(\frac{3}{2 n} \pi\right) \\
\cos \left(\frac{1}{2 n} \pi\right)
\end{array}\right] \leq\left[\begin{array}{c}
1 \\
1 \\
\vdots \\
1 \\
1
\end{array}\right] .
$$

By extracting rows of (18) for any given phase number $n$ of a multiphase system, set of $(n-1) / 2$ inequalities can be obtained that define boundaries of the dc-bus voltage utilization in the linear PWM region. An obvious difficulty is a lack of means for graphical visualization of the complete solution for any phase number greater than seven, since one deals with more than three modulation indexes (more than three $d-q$ planes). It can be 
TABLE II

Characteristic Operating Points ShOWn IN FIG. 6

\begin{tabular}{|l|c|c|c|c|c|c|c|}
\hline & $A$ & $B$ & $C$ & $D$ & $E$ & $F$ & $G$ \\
\hline$M_{1}$ & 1.0257 & 0 & 0 & 0.8851 & 0 & 0.3159 & 0.4565 \\
\hline$M_{2}$ & 0 & 1.0257 & 0 & 0.3159 & 0.8851 & 0 & 0.4565 \\
\hline$M_{3}$ & 0 & 0 & 1.0257 & 0 & 0.3159 & 0.8851 & 0.4565 \\
\hline
\end{tabular}

TABLE III

Modulation Index Values Against the Phase Number

\begin{tabular}{|c|c|c|c|c|c|}
\hline Phase number $n$ & 3 & 5 & 7 & 11 & 13 \\
\hline$M_{\max }^{*}$ & 1.1547 & 1.0515 & 1.0257 & 1.0103 & 1.0073 \\
\hline$M_{\max }$ & 1.1547 & 0.6498 & 0.4565 & 0.2876 & 0.2428 \\
\hline$[(n-1) / 2] M_{\max }$ & 1.1547 & 1.2996 & 1.3695 & 1.438 & 1.4568 \\
\hline
\end{tabular}

口 Mmax* $\square \max \square((\mathrm{n}-1) / 2)^{*} \mathrm{Mmax}$

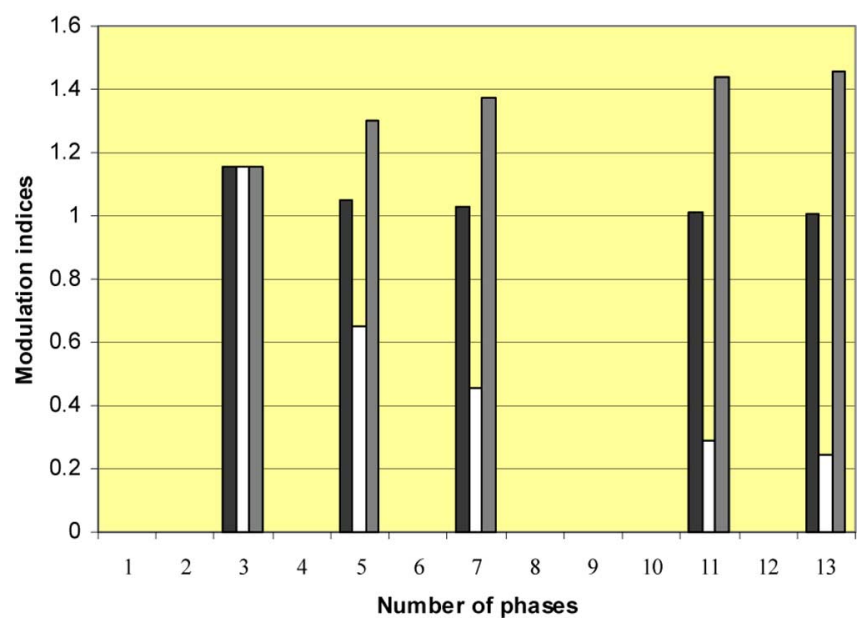

Fig. 7. Graphical illustration of the data given in Table III.

easily verified that (18) reduces to (12), (13), and (15) for the five-phase and the seven-phase system, respectively.

Using (18), the coordinates of the point in which $M_{\max }$ results (that are all the same) can be expressed as

$$
M_{\max }(n)=1 / \sum_{j=1}^{(n-1) / 2} \cos \left(\frac{2 j-1}{2 n} \pi\right) .
$$

Application of (19) in conjunction with 11-phase and 13phase systems yields the values of 0.2876 and 0.2428 , respectively. Table III illustrates numerical values for odd prime phase numbers up to 13. The first row shows maximum value of the modulation index for purely sinusoidal (single-frequency) output, which corresponds to (3) and (6), and is denoted as $M_{\max }^{*}$. The second row illustrates the maximum value of the modulation index $M_{\max }$ that can be reached simultaneously in all planes, when all planes are excited (multifrequency output). Finally, the third row shows the product of the number of planes (machines) and the second row. A graphical illustration of the data in Table III is shown in Fig. 7.

On the basis of numerical values in Table III and Fig. 7, it can be concluded that: 1) value of the maximum modulation index

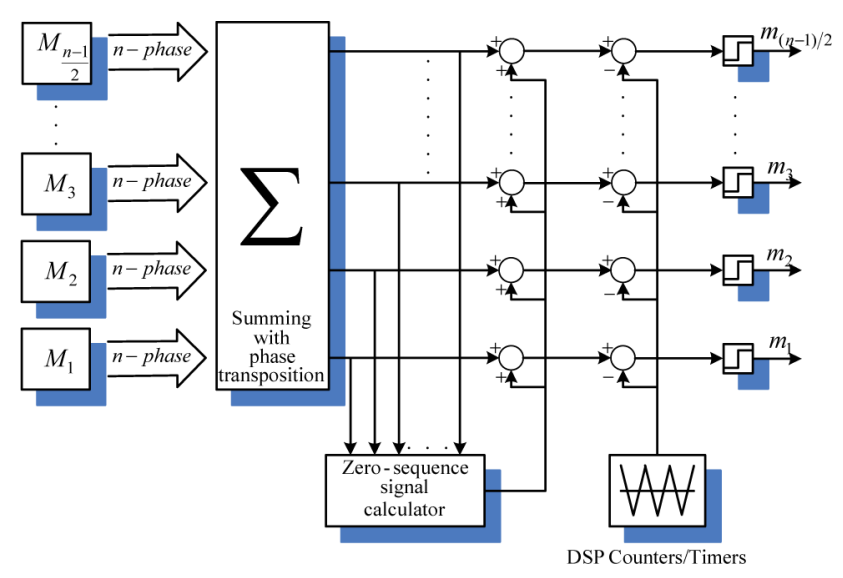

Fig. 8. Principle of carrier-based PWM for multifrequency output voltage generation with an $n$-phase VSI.

approaches unity as the number of phases increases for purely sinusoidal output voltages; 2 ) with simultaneous and equal amplitude excitation in all planes, the value of the maximum modulation index $M_{\max }$ decreases as the phase number increases; and 3) the product of the number of planes $(n-1) / 2$ and the maximum modulation index $M_{\max }$ increases as the number of phases increases, and is in the 13-phase systems $45 \%$ higher than with single-frequency excitation. This is the consequence of the phase transposition in connection of the planes, Figs. 1 and 2, (A1).

\section{EXPERIMENTAL VERIFICATION}

In order to experimentally verify the established boundaries that govern dc-bus utilization in five-phase and seven-phase VSIs, a carrier-based PWM scheme that follows the methodology of [17] is used to create switching functions $\left(m_{i}\right)$ for multiphase inverter legs. General layout of a carrier-based modulator for an $n$-phase VSI is shown in Fig. 8. On the left-hand side of Fig. 8, one has sinusoidal references for each plane, defined by means of the magnitude (i.e., modulation index) and frequency for each plane $\left(M_{i}, f_{i}\right)$. Set of these sinusoidal references is then summed using phase transposition, illustrated in Figs. 1 and 2 for the five-phase and seven-phase systems. The carrier signal is of a triangular waveform, with peak values of \pm 1 .

To explain the need for zero-sequence injection, two sets of sinusoidal references are provided at the input of the modulator in Fig. 8. The sets correspond to an operating point in the limit of the linear modulation region in Fig. 4 (five-phase system, point denoted as $Z$ ), and are such that $M_{1}=0.7$ (at $33 \mathrm{~Hz}$ ) and $M_{2}=0.5687$ (at $27 \mathrm{~Hz}$ ). Fig. 9 (upper part) illustrates the resulting modulating signals after the "summing with phase transposition" block of Fig. 8. It is evident that the modulating signals are highly asymmetrical and that they exceed the range of the carrier (i.e., over-modulation takes place). However, the instants of clamping to the upper dc-bus rail and to the lower dc-bus rail do not coincide, meaning that clamping occurs in only one of the inverter legs. To alleviate this problem and enable full dc-bus voltage utilization in the linear region, it is 

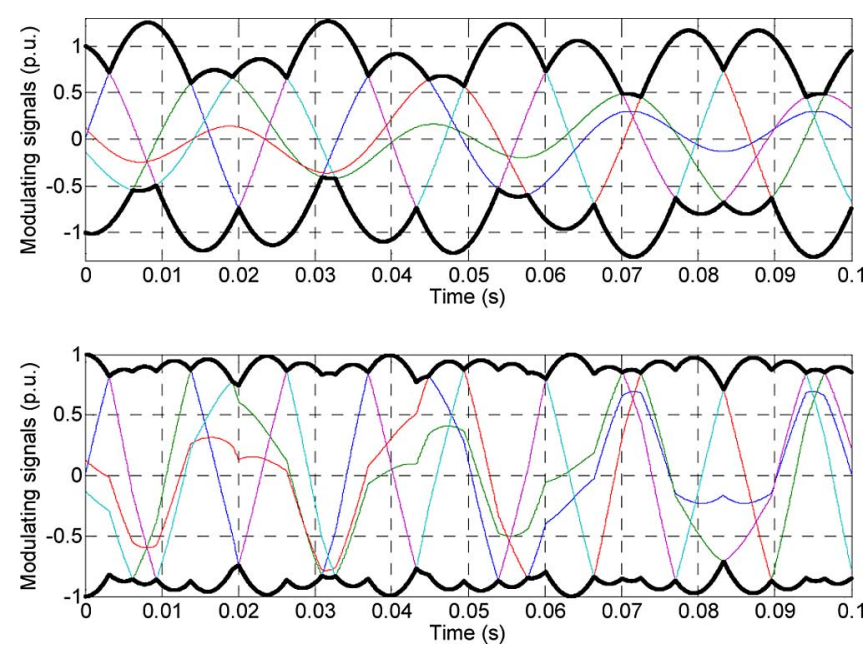

Fig. 9. Resulting modulating signals for five-phase VSI before (top) and after (bottom) zero-sequence signal injection (simulation).

necessary to modify the modulating signals by centering positive and negative peaks with respect to the mid-point of the range that they span (around zero in Fig. 9). To perform the centering, zero-sequence signal, determined by maximum and minimum values of the modulating signals

$$
z s=-\left(\frac{1}{2}\right)\left(V_{\max }+V_{\min }\right)
$$

is injected [17]. Addition of the zero-sequence signal modifies modulating signals, as shown in the bottom part of Fig. 9, and thus enables full dc-bus utilization. It can be seen that after adding zero-sequence signal, envelopes (shown as bold trace in both parts of Fig. 9) that correspond to positive and negative peak values of the modulating signals appear as mirrored images. This will guarantee that dc-bus utilization is maximized and that clamping occurs simultaneously in two inverter legs when the limit of the linear modulation region is reached. Results shown in Fig. 9 further confirm that the zero-sequence signal (20), widely used in three-phase systems, is also valid for higher phase numbers, as well as for multifrequency output voltage generation in multiphase systems. Results similar to those of Fig. 9 but for a seven-phase system, which further confirm validity of (20) for higher phase numbers with multifrequency output voltage generation, are given in Appendix B, together with the derivation of (20).

Carrier-based modulator of Fig. 8 has been implemented in TMS320F2812 DSP. Value of the dc-bus voltage is in all experiments around $600 \mathrm{~V}$, and the switching frequency is set to $5 \mathrm{kHz}$. There is no compensation of inverter dead time and semiconductor voltage drops, since these are irrelevant for the purposes of this paper (their main consequence is slightly lower output voltage than the reference). Output voltage is measured using a low-pass filter (with cutoff frequency of $1.6 \mathrm{kHz}$ ) and HP35665A dynamic signal analyzer. Only inverter voltage is shown further on (a detailed study of the steady-state modeling and behavior of the five-phase two-motor series-connected

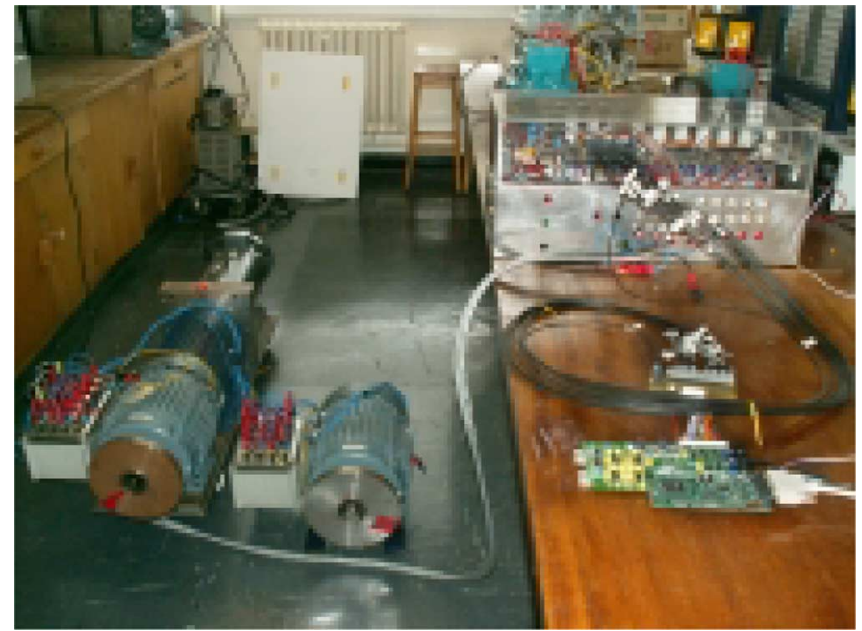

Fig. 10. Experimental setup.

drive system, including measured steady-state current and its spectrum, has been reported in [21]).

\section{A. Five-Phase VSI}

The experimental setup consists of two series-connected fivephase induction machines and a nine-phase inverter (used here in five-phase configuration), as illustrated in Fig. 10. The simplest $V / f$ control law is applied for control purposes. The basic idea in the experimental verification is that as long as the inverter operates in the linear modulation region, the output voltage will contain only frequency components that correspond to the references. Since the machines are identical and $V / f$ control law is, therefore, the same (see Appendix C), operation in the point $M_{\max }$ in Fig. 4 means operation with the same frequencies. As this would appear as a single-frequency component in the spectrum, operation in the very vicinity of the already utilized point $Z$ of Fig. 4 in the limit of the linear modulation region is examined experimentally instead. Hence, $M_{1}=0.699$ at $33 \mathrm{~Hz}$ and $M_{2}=0.5539$ at $26 \mathrm{~Hz}^{2}$

Experimentally recorded inverter phase " $A$ " voltage and its spectrum are shown in Fig. 11 for this operating condition. As can be seen from Fig. 11, the inverter generates required two fundamentals at required frequencies without any low-order harmonics, indicating that operation is in the linear modulation region. The two fundamentals, which appear in the two different planes of Fig. 1, are just a few percent below the corresponding reference values (148.3 and $117.5 \mathrm{~V} \mathrm{rms)}$, due to the uncompensated inverter nonlinearities.

In the second test, the settings are changed to $M_{1}=0.6369$ at $30 \mathrm{~Hz}$ and $M_{2}=0.5533$ at $25 \mathrm{~Hz}$. Since $M_{1}+M_{2}=1.1902>$ 1.0515 , operation is again in a point of Fig. 4, where overmodulation would have resulted had there not been phase transposition in connection of the planes in Fig. 1. Results for this operating condition of the two-motor drive are shown in Fig. 12. Once

\footnotetext{
${ }^{2} \mathrm{~A}$ slight difference in $\left(M_{i}, f_{i}\right)$ pairs of values as compared to the simulation results in Fig. 9 is due to the applied voltage boost (see Fig. 18), which was not used in simulation illustration given in Fig. 9.
} 

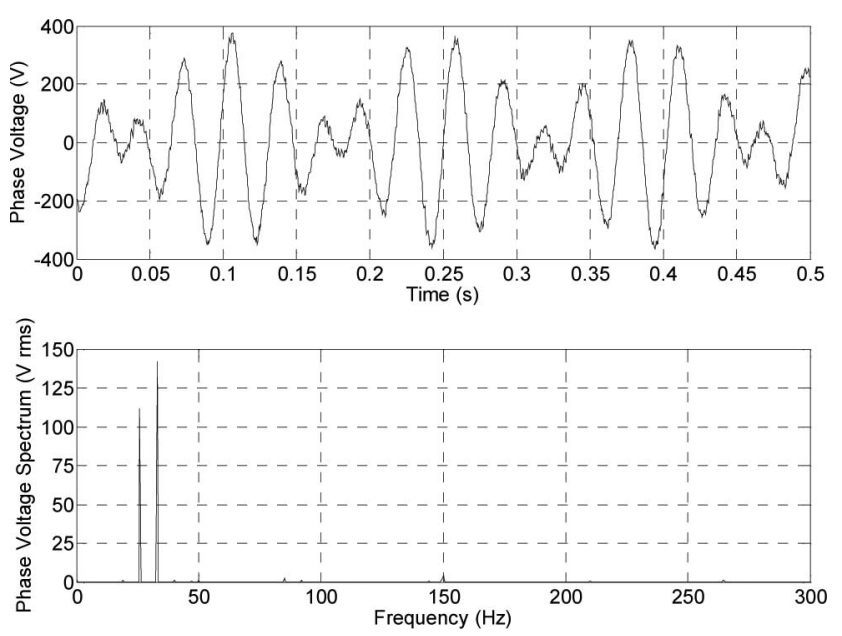

Fig. 11. Inverter phase voltage and its spectrum for operation of the seriesconnected two-motor five-phase drive with $M_{1}=0.699$ at $33 \mathrm{~Hz}$ and $M_{2}=$ 0.5539 at $26 \mathrm{~Hz}$ (immediate vicinity of point $Z$ in Fig. 4).
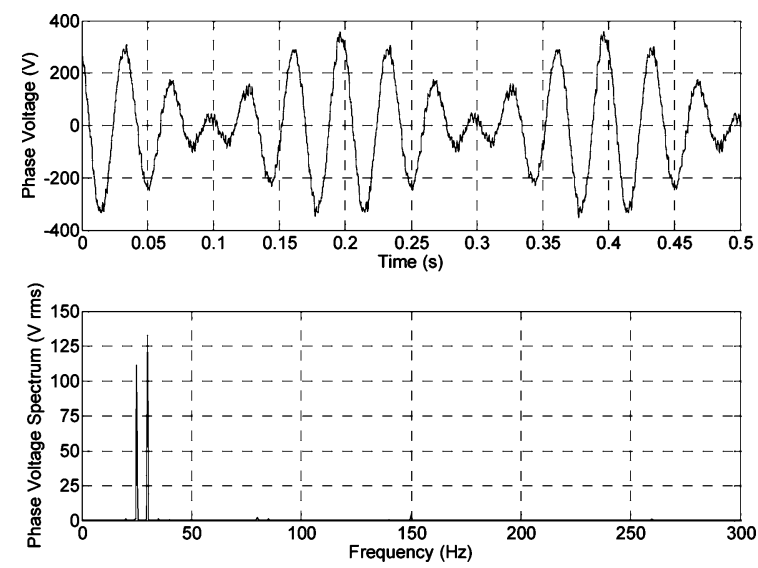

Fig. 12. Inverter phase voltage and its spectrum for operation of the seriesconnected two-motor five-phase drive with $M_{1}=0.6369$ at $30 \mathrm{~Hz}$ and $M_{2}=$ 0.5533 at $25 \mathrm{~Hz}$ (within the shaded area in Fig. 4).

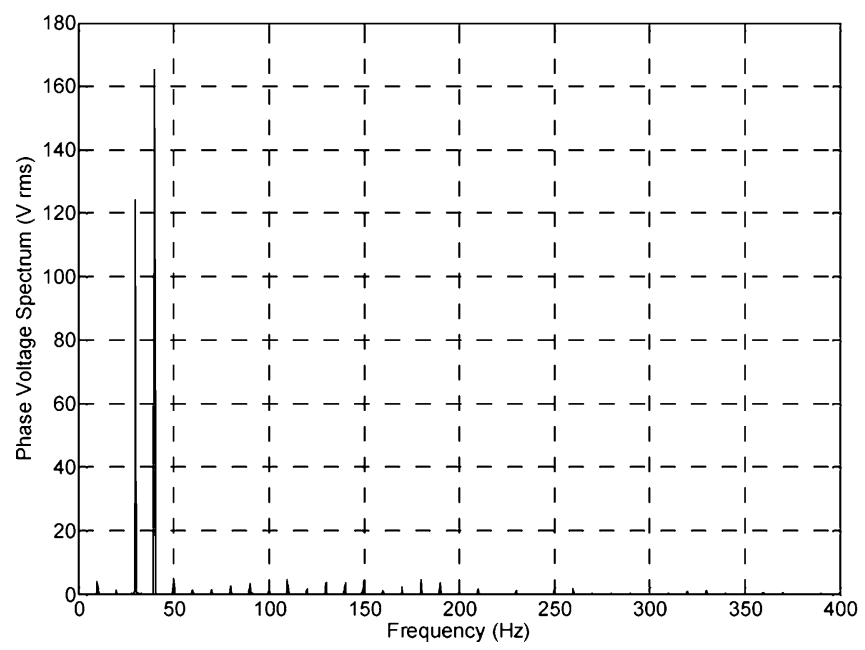

Fig. 13. Inverter phase voltage spectrum for operation of the series-connected two-motor five-phase drive with $M_{1}=0.6369$ at $30 \mathrm{~Hz}$ and $M_{2}=0.8444$ at $40 \mathrm{~Hz}$ (overmodulation; outside the shaded area of Fig. 4).
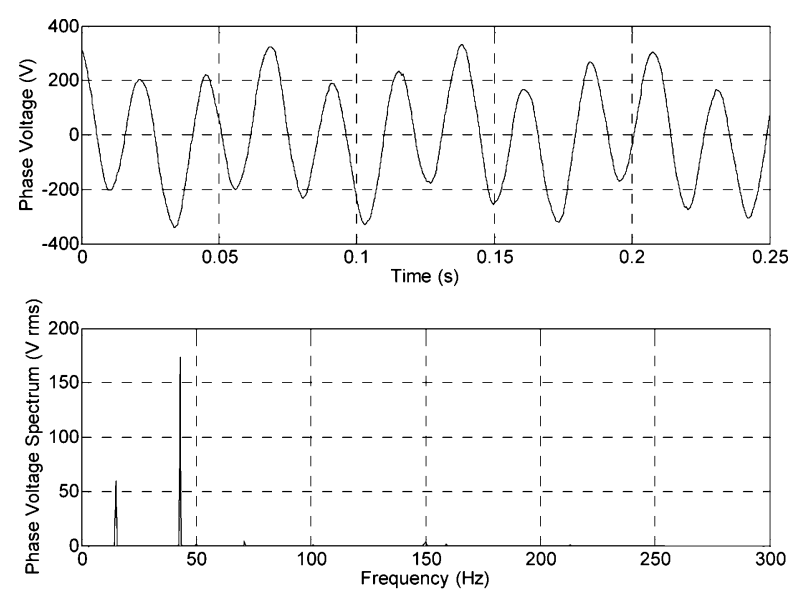

Fig. 14. Phase voltage and its spectrum for operation of the seven-phase VSI in the limit of the linear modulation region when only the first two planes are excited $\left(M_{1}=0.885\right.$ at $43 \mathrm{~Hz}$ and $M_{2}=0.315$ at $15 \mathrm{~Hz}$; point $D$ in Figs. 5 and 6).

more, spectrum is practically perfectly clean, with only two fundamentals of just slightly lower values than the references $(135.1 \mathrm{~V}$ at $30 \mathrm{~Hz}$ and $117.4 \mathrm{~V}$ at $25 \mathrm{~Hz}$ ). Thus, the inverter operates again in the linear PWM region.

Next, operating point is pushed outside the shaded region of Fig. 4 by selecting $M_{1}=0.6369$ at $30 \mathrm{~Hz}$ and $M_{2}=0.8444$ at $40 \mathrm{~Hz}$. Spectrum of the inverter voltage, shown in Fig. 13, now contains a whole range of low-order harmonics (including subharmonics ${ }^{3}$ ), thus confirming that the inverter operates outside the linear modulation region. Also, achieved values of the two fundamentals in the inverter output voltage are now substantially bellow the corresponding references (135.1 and $179.1 \mathrm{~V}$ $\mathrm{rms}$ ), since the dc-bus voltage is now too low and the modulator gain is not unity any more.

\section{B. Seven-Phase VSI}

The same inverter of Fig. 10, configured as a seven-phase, is used again. The load is, however, now static and consists of series connection of light bulbs and lamp ballasts in each phase. Voltage references for individual phases are summed according to the plane connection diagram of Fig. 2. Reference frequencies are selected arbitrarily. Three different operating conditions are examined.

Modulation index and frequency for the plane $d_{3}-q_{3}$ are at first set to zero, and the limits illustrated in Fig. 5 are explored. Modulation indexes in the two planes are, therefore, set to $M_{1}=$ 0.885 (at $43 \mathrm{~Hz}$ ) and $M_{2}=0.315$ (at $15 \mathrm{~Hz}$ ). This corresponds to the point $D$ in Figs. 5 and 6. Measured phase-to-neutral voltage at the inverter output is illustrated in Fig. 14, together with the spectrum. It can be seen that the spectrum contains only the two components at frequencies of the references, without any other low-order harmonics. Hence, the inverter does operate in the linear modulation region, as predicted in Fig. 5, for this operating point. The rms values in the spectrum of Fig. 14 are a

\footnotetext{
${ }^{3}$ Detailed analysis of the output voltage harmonic content in overmodulation is beyond the scope of this paper
} 

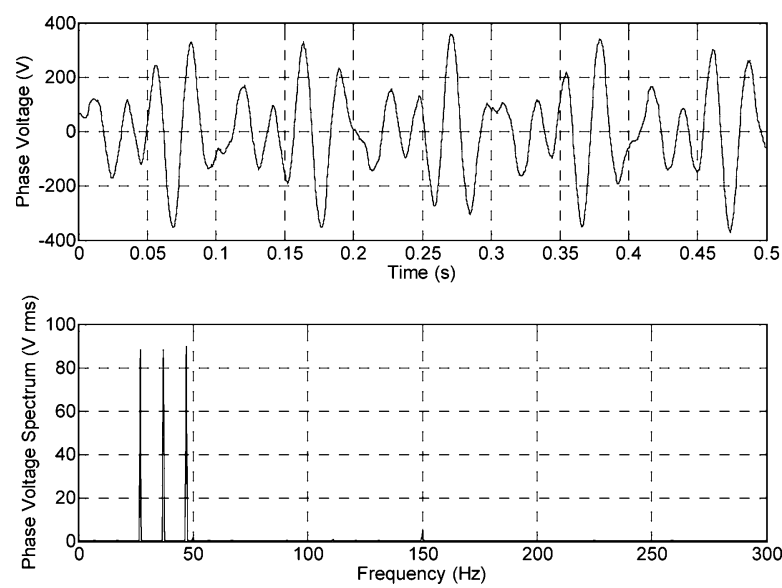

Fig. 15. Phase voltage and its spectrum for operation of the seven-phase VSI in the limit of the linear modulation region when all three planes are excited ( $M_{1}=M_{2}=M_{3}=0.4565$ at 27, 37, and $47 \mathrm{~Hz}$; point $G$ in Fig. 6).
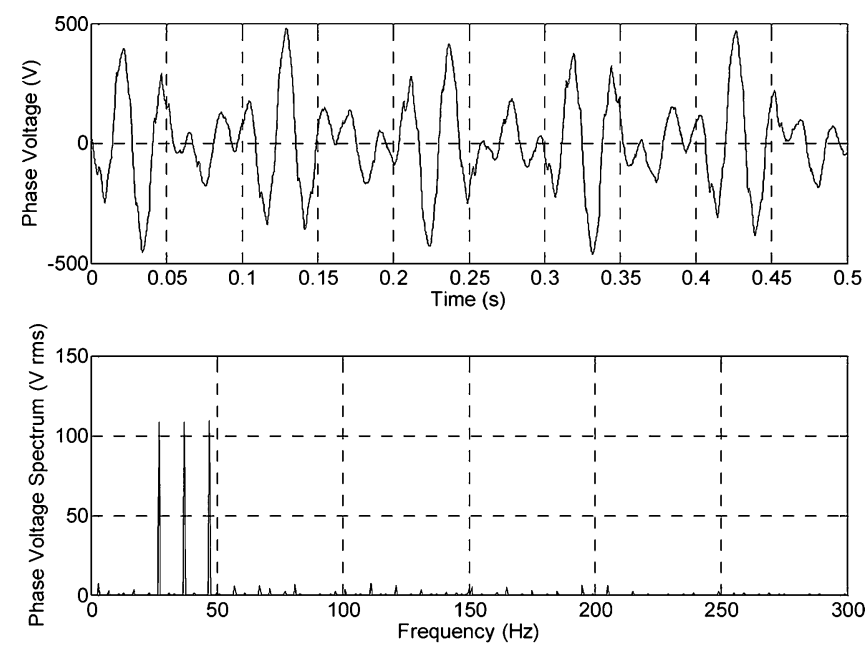

Fig. 16. Phase voltage and its spectrum for operation of the seven-phase VSI in the overmodulation region $\left(M_{1}=M_{2}=M_{3}=0.65\right.$ at 27,37 , and $47 \mathrm{~Hz}$; operating point outside the volume of Fig. 6).

couple of percent lower that the corresponding rms references (187.7 and $66.8 \mathrm{~V})$.

In the second experiment, operation in point $G$ of Fig. 6 is examined. Modulation indexes are, therefore, set to the same value $M_{1}=M_{2}=M_{3}=0.4565$, and frequencies are arbitrarily selected as 27,37 , and $47 \mathrm{~Hz}$, respectively, in the three planes. Experimental results are shown in Fig. 15. As can be seen, all three fundamentals are correctly generated, are of the same rms values (again just slightly below the reference, which is $96.8 \mathrm{~V}$ rms), and the spectrum does not show existence of any other low-order harmonics, thus confirming that the inverter operates in the linear modulation region.

To illustrate the operation in the overmodulation, an operating point outside the volume of Fig. 6 is considered in the third experiment. The frequencies of three sets of references are kept the same as in the previous case, but modulation indexes are increased to $M_{1}=M_{2}=M_{3}=0.65$. Phase voltage and its spectrum are now as shown in Fig. 16. It is obvious that the inverter now operates in the overmodulation region, since the spectrum contains a whole range of low-order harmonics (including subharmonics).

\section{CONCLUSION}

The paper extends the basic principle of determination of the limit of the linear modulation region, widely utilized for threephase inverters, to multiphase inverters with an arbitrary prime number of phases. It is shown that from the point of view of the dc-bus voltage utilization, the supply of a machine with a concentrated stator winding is analogous to multiphase seriesconnected multimotor drives (that use machines with sinusoidal winding distribution). The inverter is required to generate more than one frequency component at the output, such that these voltage components appear in different and mutually orthogonal planes of a multidimensional space. Due to the phase transposition that exists between these planes, dc-bus utilization in the linear modulation region is better than it would have been had all the required voltage components belonged to the same plane.

It is shown that the dc-bus voltage utilization of a five-phase VSI is governed with an area in the $\left(M_{1}, M_{2}\right)$ plane. In the case of a seven-phase VSI, linear PWM is obtainable as long as the three modulation indexes determine a point that belongs to the volume in the $\left(M_{1}, M_{2}, M_{3}\right) 3$-D space. The principle is further extended to higher prime phase numbers, where a corresponding graphical representation is not possible any more.

Developed method is entirely independent of the applied method of pulsewidth modulation, and is equally applicable to both space vector and carrier-based PWM. Theoretical considerations are verified experimentally using a series-connected two-motor five-phase induction motor drive and a static load supplied from a seven-phase VSI.

\section{APPENDIX A}

The analogy between the series-connected multimotor drives and concentrated winding machines from the point of view of the VSI stems from the use of the decoupling (Clarke's) transformation matrix $\underline{C}$ [19], which, for a five-phase system, has the form

$$
\underline{C}=\sqrt{\frac{2}{\frac{2}{5}}} \begin{gathered}
q_{1} \\
d_{2} \\
q_{2} \\
0
\end{gathered} \mid\left[\begin{array}{ccccc}
1 & \cos \alpha & \cos 2 \alpha & \cos 3 \alpha & \cos 4 \alpha \\
0 & \sin \alpha & \sin 2 \alpha & \sin 3 \alpha & \sin 4 \alpha \\
1 & \cos 2 \alpha & \cos 4 \alpha & \cos 6 \alpha & \cos 8 \alpha \\
0 & \sin 2 \alpha & \sin 4 \alpha & \sin 6 \alpha & \sin 8 \alpha \\
1 / \sqrt{2} & 1 / \sqrt{2} & 1 / \sqrt{2} & 1 / \sqrt{2} & 1 / \sqrt{2}
\end{array}\right]
$$

Here $\alpha=72^{\circ}$. By comparing (A1) with the arrangement of Fig. 1, it can be seen that the placement of the second machine corresponds to the second pair of rows in (A1). This corresponds to the second motor in a series-connected five-phase two-motor drive. On the other hand, by applying (A1) in conjunction with a five-phase set of variables that contain low-order harmonics in addition to the fundamental, harmonic mapping shown in Table I for the five-phase system results. In other words, the second pair of rows in (A1) produces harmonics in the $d_{2}-q_{2}$ plane, which are the third, seventh, etc., for a five-phase system. 


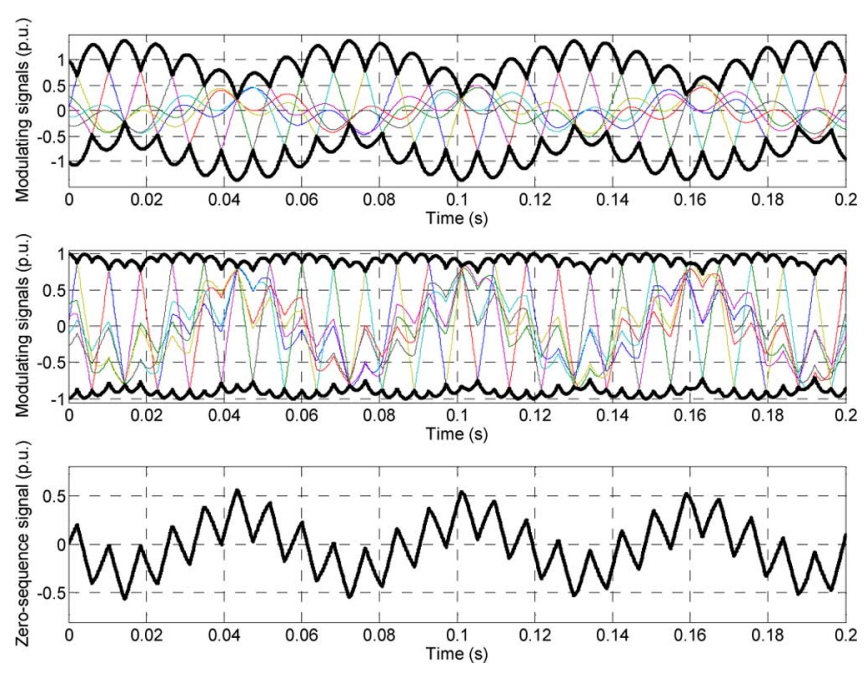

Fig. 17. Resulting modulation signals for seven-phase VSI: before (top) and after (middle) zero sequence injection, and zero-sequence signal (bottom).

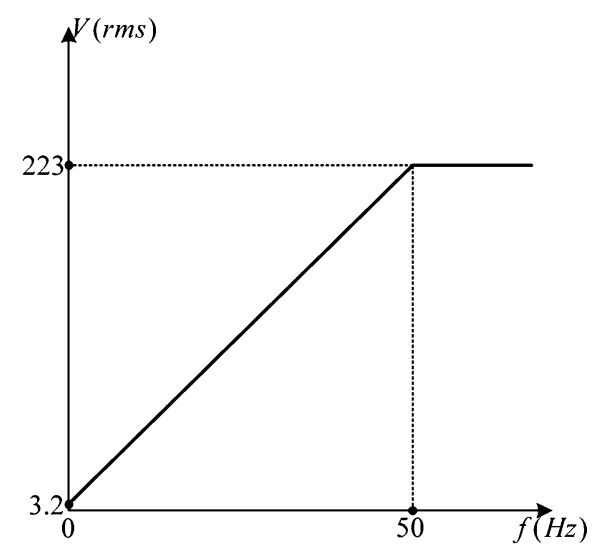

Fig. 18. $\quad V / f$ control law used for five-phase induction machines (dc-bus voltage $=600 \mathrm{~V})$.

\section{APPENDIX B}

An illustration of the zero-sequence injection described with (20) is provided first for the seven-phase system. The same conditions as in the experimental results of Fig. 15 are considered, so that $M_{1}=M_{2}=M_{3}=0.4565$ at 27, 37, and $47 \mathrm{~Hz}$. Resulting modulating signals before and after zero-sequence injection are shown in Fig. 17. As can be seen from the results, application of the zero-sequence injection according to (20) has again the effect of returning modulating signals into the region $(-1,1)$. The zero-sequence signal obtained by means of $(20)$ is also shown in Fig. 17. Due to the modulating signals that contain three sinusoidal components of different frequencies, zero-sequence signal is a rather complicated function.

Expression (20) is valid regardless of the phase number and regardless of the form of the original modulating functions. To prove this statement, consider a set of modulating signals of any form, for any phase number. In any particular instant in time, it is possible to find the maximum and minimum values within this set, $V_{\max }$ and $V_{\min }$. The role of the zero-sequence injection is to alter these values, so that they become after zero-sequence injection $V_{\max }^{\prime}, V_{\min }^{\prime}$, where

$$
\begin{aligned}
& V_{\max }^{\prime}=V_{\max }+z s \\
& V_{\min }^{\prime}=V_{\min }+z s .
\end{aligned}
$$

Since the zero-sequence injection performs centering within the interval $(-1,1)$, then after zero-sequence injection, one has

$$
V_{\max }^{\prime}=-V_{\min }^{\prime}
$$

By substituting (B1) into (B2), one obtains

$$
z s=-\left(\frac{1}{2}\right)\left(V_{\max }+V_{\min }\right) .
$$

\section{APPENDIX C}

The $V / f$ control law, applied in conjunction with the twomotor five-phase series-connected drive in experiments, is illustrated in Fig. 18.

\section{REFERENCES}

[1] E. Levi, R. Bojoi, F. Profumo, H. A. Toliyat, and S. Williamson, "Multiphase induction motor drives-A technology status review," IET Electr. Power Appl., vol. 1, no. 4, pp. 489-516, 2007.

[2] B. C. Mecrow, A. G. Jack, D. J. Atkinson, S. R. Green, G. J. Atkinson, A. King, and B. Green, "Design and testing of a four-phase fault-tolerant permanent magnet machine for an engine fuel pump," IEEE Trans. Energy Convers., vol. 19, no. 4, pp. 671-678, Dec. 2004.

[3] J. W. Kelly, E. G. Strangas, and J. M. Miller, "Multiphase space vector pulse width modulation," IEEE Trans. Energy Convers., vol. 18, no. 2, pp. 259-264, Jun. 2003.

[4] P. S. N. de Silva, J. E. Fletcher, and B. W. Williams, "Development of space vector modulation strategies for five-phase voltage source inverters," in Proc. Inst. Elect. Eng. Power Electron., Mach. Drives Conf. PEMD, Edinburgh, U.K., 2004, pp. 650-655.

[5] G. Grandi, G. Serra, and A. Tani, "Space vector modulation of a sevenphase voltage source inverter," in Proc. Int. Symp. Power Electron., Elec. Drives, Autom. Motion SPEEDAM, Taormina, Italy, CD-ROM, 2006, pp. S8-6-S8-13.

[6] A. Iqbal and E. Levi, "Space vector PWM techniques for sinusoidal output voltage generation with a five-phase voltage source inverter," Electr. Power Compon. Syst., vol. 34, no. 2, pp. 119-140, 2006.

[7] D. Dujic, E. Levi, M. Jones, G. Grandi, G. Serra, and A. Tani, "Continuous PWM techniques for sinusoidal voltage generation with seven-phase voltage source inverters," in Proc. IEEE Power Electron. Spec. Conf. PESC, Orlando, FL, 2007, pp. 47-52.

[8] X. Kestelyn, E. Semail, and J. P. Hautier, "Multi-phase system supplied by SVM VSI: A new fast algorithm to compute duty cycles," EPE J., vol. 14, no. 3, pp. 25-31, 2004.

[9] S. Xue and X. Wen, "Simulation analysis of two novel multiphase SVPWM strategies," in Proc. IEEE Int. Conf. Ind. Technol. ICIT, Honk Kong, 2005, pp. 1401-1406.

[10] A. Iqbal, E. Levi, M. Jones, and S. N. Vukosavic, "Generalised sinusoidal PWM with harmonic injection for multi-phase VSIs," in Proc. IEEE Power Elec. Spec. Conf. PESC, Jeju, Korea, 2006, pp. 2871-2877.

[11] Y. Zhao and T. A. Lipo, "Space vector PWM control of dual three-phase induction machine using vector space decomposition," IEEE Trans. Ind. Appl., vol. 31, no. 5, pp. 1100-1109, Sep./Oct. 1995.

[12] O. Ojo and G. Dong, "Generalized discontinuous carrier-based PWM modulation scheme for multi-phase converter-machine systems," in Proc. IEEE Ind. Appl. Soc. Annu. Meeting IAS, Hong Kong, 2005, pp. 1374 1381.

[13] H. M. Ryu, J. H. Kim, and S. K. Sul, "Analysis of multiphase space vector pulse-width modulation based on multiple d-q spaces concept," IEEE Trans. Power Electron., vol. 20, no. 6, pp. 1364-1371, Nov. 2005.

[14] O. Ojo, G. Dong, and Z. Wu, "Pulse-width modulation for five-phase converters based on device turn-on times," in Proc. IEEE Ind. Appl. Soc. Annu. Meeting IAS, Tampa, FL, 2006, pp. 627-634. 
[15] E. Levi, M. Jones, S. N. Vukosavic, and H. A. Toliyat, "A novel concept of a multiphase, multi-motor vector controlled drive system supplied from a single voltage source inverter," IEEE Trans. Power Electron., vol. 19, no. 2, pp. 320-335, Mar. 2004.

[16] E. Levi, M. Jones, S. N. Vukosavic, and H. A. Toliyat, "Operating principles of a novel multi-phase multi-motor vector controlled drive," IEEE Trans. Energy Convers., vol. 19, no. 3, pp. 508-517, Sep. 2004.

[17] A. Iqbal, E. Levi, M. Jones, and S. N. Vukosavic, "A PWM scheme for a five-phase VSI supplying a five-phase two-motor drive," in Proc. IEEE Ind. Elec. Soc. Аnпu. Meeting IECON, Paris, France, 2006, pp. 25752580.

[18] A. Iqbal and E. Levi, "Space vector PWM for a five-phase VSI supplying two five-phase series-connected machines," in Proc. Int. Power Electron. Motion Control Conf. EPE-PEMC, Portoroz, Slovenia, 2006, pp. 222227.

[19] D. C. White and H. H. Woodson, Electromechanical Energy Conversion. New York: Wiley, 1959.

[20] G. D. Holmes and T. A. Lipo, Pulse Width Modulation for Power Converters-Principles and Practice. (IEEE Press Series on Power Engineering) Piscataway, NJ: Wiley, 2003.

[21] E. Levi, M. Jones, S. N. Vukosavic, and H. A. Toliyat, "Steady state modelling of series-connected five-phase and six-phase two-motor drives," in Proc. IEEE Ind. Appl. Soc. Annu. Meeting IAS, Tampa, FL, 2006, pp. 415 422.

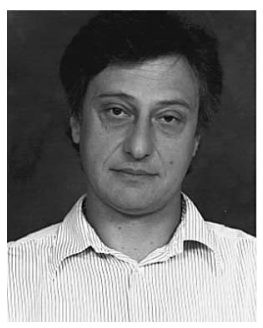

Emil Levi (S'89-M'92-SM'99) received the M.Sc. and $\mathrm{Ph} . \mathrm{D}$. degrees from the University of Belgrade, Belgrade, Yugoslavia, in 1986 and 1990, respectively, all in electrical engineering.

From 1982 to 1992 , he was with the Department of Electrical Engineering, University of Novi Sad, Novi Sad, Serbia. Since 1992, he has been with Liverpool John Moores University, Liverpool, U.K., where he is currently a Professor of Electric Machines and Drives.

Prof. Levi was an Editor of the IEEE TRANSACTIONS on ENERGY CONVERSION, an Associate Editor of the IEEE TRANSACTIONS ON INDUSTRIAL ELECTRONICS, and a member of the Editorial Board of the IET Electric Power Applications.

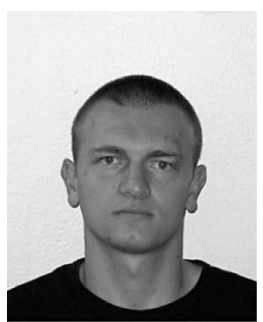

Drazen Dujic (S'03) received the B.Eng. and M.Sc. degrees, both in electrical engineering from the University of Novi Sad, Novi Sad, Serbia, in 2002 and 2005 , respectively. He is currently working toward the Ph.D. degree at Liverpool John Moores University, Liverpool, U.K.

From 2002 till 2006, he was with the Department of Electrical Engineering, University of Novi Sad, as a Research Assistant. His current research interests include control of power converters and highperformance electric motor drives.

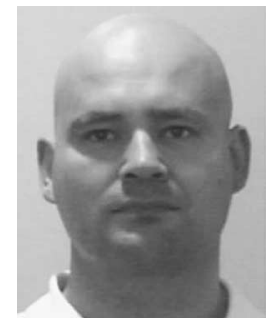

Martin Jones (M'07) received the B.Eng. (first class honors) and Ph.D. degrees in electrical engineering from Liverpool John Moores University, Liverpool, U.K., in 2001 and 2005, respectively.

He is currently with Liverpool John Moores University as a Postdoctoral Research Associate. His current research interests include high performance ac drives.

Dr. Jones was a recipient of the Institution of Electrical Engineers (IEE) Robinson Research Scholarship for his Ph.D. studies.

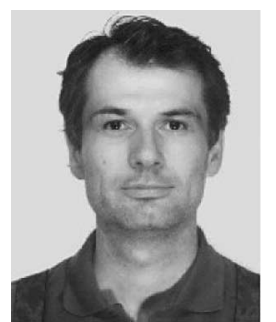

Gabriele Grandi (M'00) received the M.Sc. (cum laude) and Ph.D. degrees from the Faculty of Engineering, University of Bologna, Bologna, Italy, in 1990 and 1994, respectively, both in electrical engineering.

Since 1995, he is with the Department of Electrical Engineering, University of Bologna, where he is currently an Associate Professor. His current research interests include power electronic circuits and power electronic converters for renewable energy sources. 